EGU2020-9351

https://doi.org/10.5194/egusphere-egu2020-9351

EGU General Assembly 2020

(c) Author(s) 2020. This work is distributed under

the Creative Commons Attribution 4.0 License.

\title{
Eastward Tectonic Escape of Sicily Microplate: preliminary results
}

Giulia Penza ${ }^{1}$, Chiara Macchiavelli ${ }^{2}$, Pietro Paolo Pierantoni ${ }^{1}$, and Eugenio Turco ${ }^{1}$

${ }^{1}$ University of Camerino, School of Science and Technology- Geology Division, Via Gentile III da Varano, 62032 CAMERINO (MC)-ITALY.

${ }^{2}$ Group of Dynamics of the Lithosphere, Institute of Earth Sciences Jaume Almera, Structure and Dynamics of the Earth, BARCELONA-SPAIN

The complex processes affecting the Tyrrhenian-Apennine System are inevitably reflected in Sicily, here considered as an independent plate starting from $5 \mathrm{Ma}$ and located between Europe and Africa plates and Calabria microplate.

In particular the retreat of the Adriatic-Ionian slab and its fragmentation involve Sicily in a process of escape towards east-southeast due to the space that the slab is creating. At the same time Africa acts as an intender during its convergence with the European plate.

We show here the preliminary results of a study that aims to reconstruct the kinematic evolution of Sicily and its role in the framework of the Tyrrhenian-Apennine System.

First of all we found the margins of the plate, searching for lithospheric structures that can be considered as plate boundaries, using different types of data (high resolution bathymetric maps, seismic sections, geodetic data, focal mechanism of recent earthquakes, gravimetric maps, lithosphere thickness maps...) together with the literature.

The margins are:

-The Sicily Channel, characterized by a series of pull-apart basins related to a dextral trascurrent zone (Sicily-Africa margin);

-The Malta escarpment and the Taormina Line characterized by transpression (Sicily-Calabria margin);

-The Drepano-Ustica seamount also characterized by transpression (Sicily Europe margin).

Starting from the structures in the Sicily Channel, we found the Euler pole of rotation between Sicily and Africa using the GPlates software. Thanks to the software we were able to find also SicilyEurope and Sicily-Calabria poles and the velocity vectors.

Finally, we compared the Euler poles and the velocity vectors with the geological data, trying the best fit of the two and better refine the model. 
Key Words: Sicily microplate, Sicily Channel, Malta Escarpment, Tyrrhenian-Apennine System. 